\title{
COHESION, FRACTURE AND BOND - UNDERSTANDING THE DATA FROM THE VIALIT COHESION PENDULUM TEST AND OTHER FRACTURE TESTS FROM AN ANALYSIS OF RHEOLOGICAL PROPERTIES
}

Geoffrey M. Rowe Abatech Inc., PO Box 356, Blooming Glen, PA 18911, U.S.A. Email: growe@abatech.com

doi: 10.2478/ijpeat-2013-0006

\begin{abstract}
The Vialit Cohesion Pendulum has been used for many years in Europe as a tool for assessing modified asphalt binders with a particular emphasis on chip seal/surfacing dressing applications. The cohesion measured in this device has been considered as an indicator of quality of the base asphalt binder and subsequent polymer formulation. This test demonstrates a transition between brittle and ductile failure of binder systems. When a test of this kind is compared to other binder tests, it is possible to deduce the impact that the high rate of loading in the Vialit Cohesion Pendulum test has on the test results. Data have been developed on a series of SHRP core asphalt binders and these are compared to master curves developed with the same binders. A discussion will follow on how the fracture of asphalt binder and mixture is both rate and temperature dependent and that this parameter always needs that consideration to truly evaluate the meaning of test data. A test of this nature, while founded partly on an empirical data base of use, can be better explained and understood with consideration of the speed of loading and temperature effects that allows the translation of fracture temperatures at one condition to those at another. The results from this type of evaluation offer better understanding of criteria such as fatigue, fracture and bond of asphalt binders and mixtures.
\end{abstract}

\section{Introduction}

The importance of time of loading and temperature in a rheological parameter has assisted with the understanding of ultimate asphalt binder (termed bitumen in the UK and Europe) properties has been recognized for over 50-years. Heukelom (1966) demonstrated how asphalt binder properties can be related to binder ultimate properties defined as tensile strength and strain at break. In addition, he also extended this work to asphalt mixtures where the tensile strength and strain at break was normalized by the maximum strength and strain for a particular mixture. The rheological parameter used by Heukelom was the binder stiffness ( $\mathrm{Sb}$ ) defined by van der Poel (1954). This parameter effectively captures both the effect of loading time, whether expressed as frequency or time, and temperature. Other workers have shown that a parameter that captures both loading time and frequency captures the fatigue and fracture properties. For example, Smith (1958) demonstrated how this can describe the fracture properties of a Styrene-Butadiene material tested over a very wide range of conditions. In his work, he normalized the data by considering the strain rate (which captures the time effects) multiplied by a shift parameter (to capture the temperature effects). Anderson et al. (1993) showed that a stiffness parameter (secant modulus) could be applied with the direct tension test. 
The use binder stiffness to capture the time and temperature effects of asphalt materials is elegant since binders are specified with stiffness parameters and these numerical values are familiar. This method lends itself to a better understanding of the material properties and appears to be intuitive. Heukelom showed that the binder stiffness that corresponded to the peak strength of the material, as shown in Figure 1, corresponded to a complex modulus of the binder, $G^{*}$, value of approximately $15 \mathrm{MPa}$. Heukelom further developed his work with respect to mixtures and showed a similar plot where asphalt mixture strength, normalized with respect to the peak mixture strength for given mixture, multiple mixtures can all be compared on the same master curve plot. This initial work conducted by Heukelom pointed to the importance of expressing ultimate properties with consideration to both time of loading and temperature.

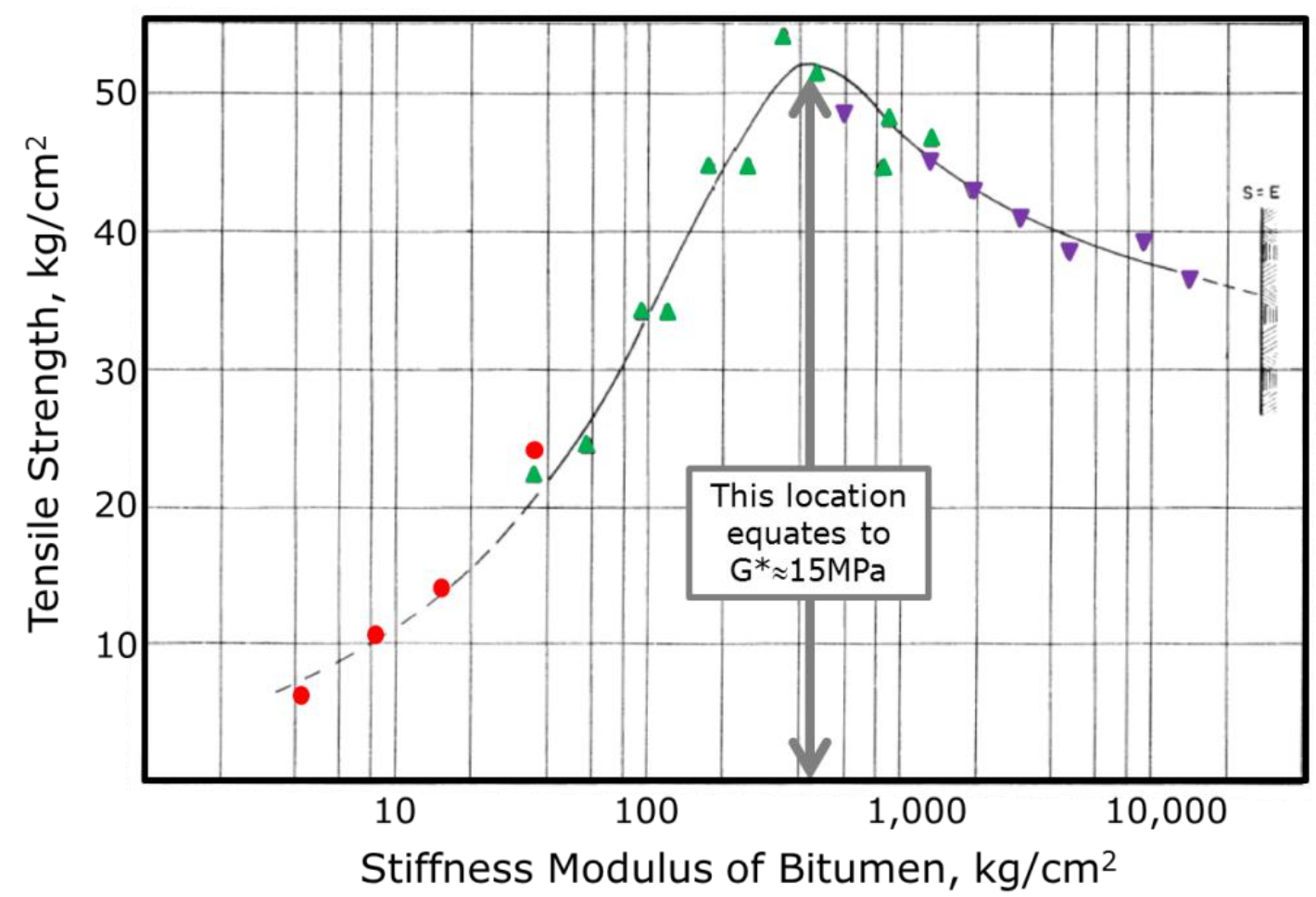

Figure 1. Tensile strength versus stiffness of asphalt binder (after Heukelom, 1966)

The importance of this time-temperature shifting can be further demonstrated by looking at tests such as the Fénix tests developed in Spain (Pérez-Jiménez et al., 2012) where, in this case, mixture stiffness is being used to normalize the data with respect to time and temperature. This work shows that peak energy appears to occur at a given mixture stiffness regardless of the mixture type.

Similar data have previously been obtained by Rowe and Sharrock (2004) from an extended analysis of data developed as part of a study of filled systems (Rayner and Rowe, 2004). In this analysis, it was observed that if the maximum energy associated with fracture in a Direct Tension Tester (DTT) test occurred at a relaxation modulus, $\mathrm{E}(\mathrm{t})$, between $7 \mathrm{MPa}$ and $20 \mathrm{MPa}$ as shown in Figure 2. The $\mathrm{E}(\mathrm{t})$ for each data point was calculated from a master curve derived from the master curve developed for each material from a combination of Dynamic hear Rheometer (DSR) and Bending Beam 
Rheometer (BBR) data. The $\mathrm{G}(\mathrm{t})$ was then obtained at the time of failure in the DTT test by computing this value from a fit of the relaxation spectra (Baumgaertel and Winter, 1989) to the master curve. E(t) was then computed assuming a Poisson's ratio of 0.5 . Unlike the earlier plot developed by Heukelom, the plot drops to values close to zero at either side of the peak energy. At high stiffness, the material is behaving in a brittle manner whereas, at low stiffness, viscous flow occurs. In both cases, little energy is used to initiate the failure.

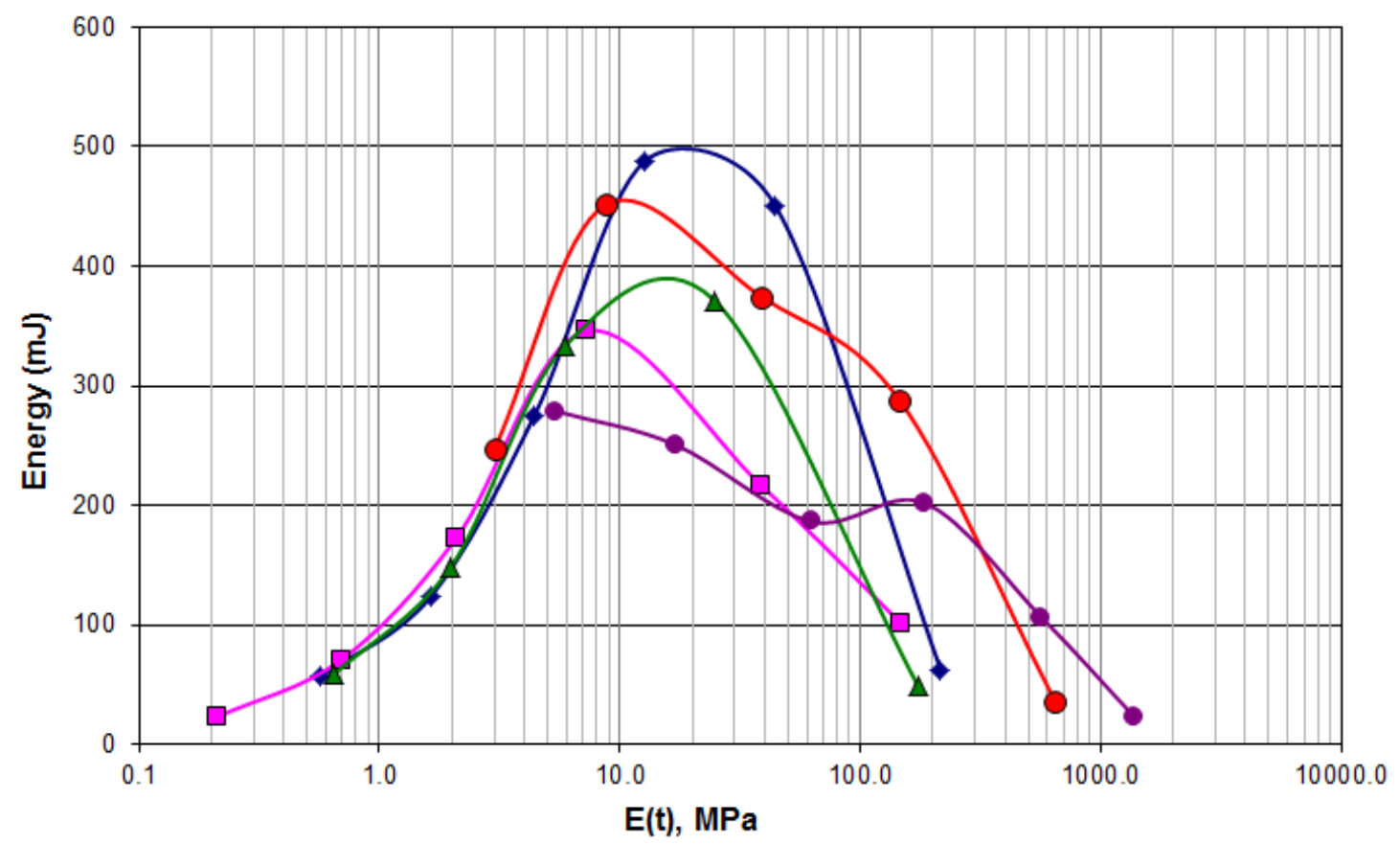

Figure 2. Data from various filled binder systems tested in the Direct Tension test with energy plotted against $\mathbf{E}(\mathbf{t})$

The Vialit pendulum test, which is standardized in EN 13588 (2008), a small sample of asphalt binder is struck by a pendulum traveling at a relatively high speed, around $4.4 \mathrm{~m} / \mathrm{s}$. Two fracture surfaces are created and the energy absorbed by the specimen to create the two fraction fracture surfaces is recorded. The cohesion test is conducted at multiple temperatures and a plot of cohesion versus temperature is obtained. Characteristic values are taken from this plot which are; 1) the maximum cohesion, 2) temperature at which the maximum cohesion occurs and 3) the range over which a minimum cohesion is achieved.

Various specifications exist for this testing, for example the European standards EN 13808 (2005) and EN 15322 (2009) both use this test as a basis for the CE marking (Conformité Européene - indicating conformance with European specifications) of polymer-modified binders for the intended use of surface treatments. The Highways Agency et al. (2008) in the United Kingdom has a specification for highway works. In these specifications, determination of cohesion on bituminous binders is required for certain types of binders. The applications of this test are mainly limited to the performance of polymer-modified binder in surface treatments and with some limited uses in other areas, for example bond coats.

Figure 3 shows the test apparatus in various configurations. In the specification standards, cohesion is calculated by the consideration of the conservation of energy 
and the conversion of potential energy to kinetic energy and vice versa. Figure 4 shows a typical plot produced by a producer of polymer-modified footway surface dressing emulsion with some characteristic peak values shown on the curve.
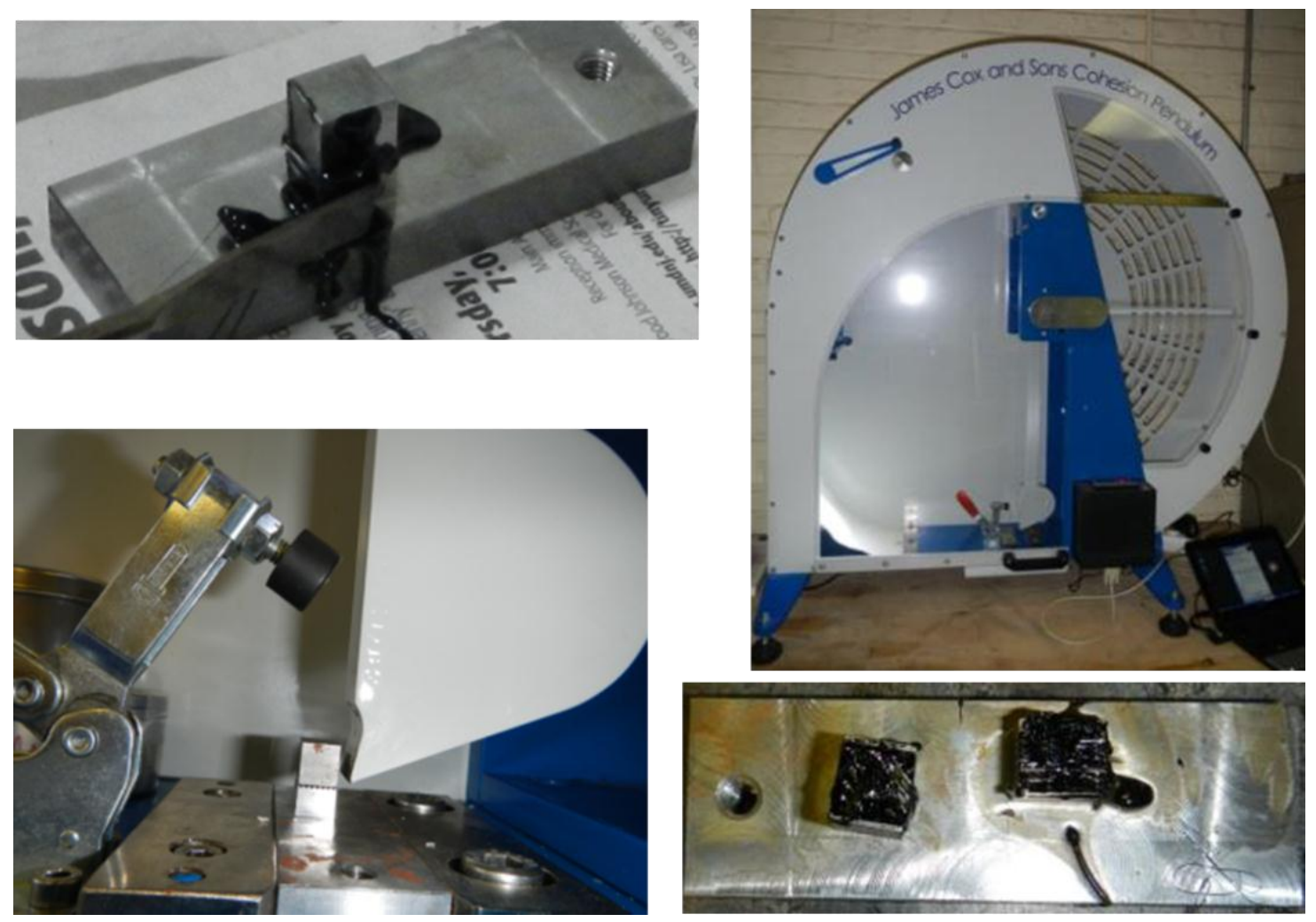

Figure 3. Trimming a sample sandwiched between two blocks (top left), general view of apparatus (top right), pendulum sticking top block (bottom left) and fractured surfaces (bottom right)

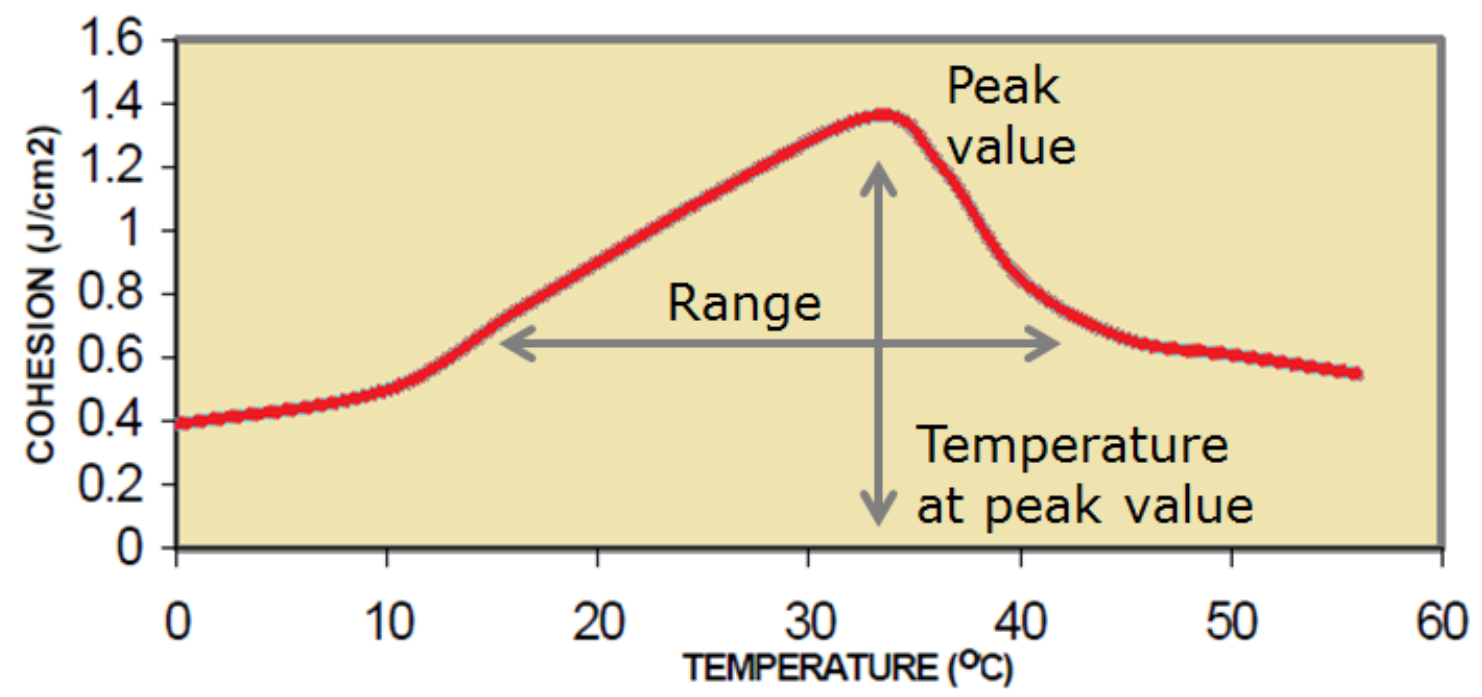

Figure 4. Typical result produced by a materials supplier (after Total Bitumen, 2007)

When data from various sources (Total Bitumen, 2007; British Board of Agrément, 2010; Surrey County Council, 2011) were reviewed, it was observed that a relationship between penetration at $25^{\circ} \mathrm{C}$ and maximum cohesion temperature 
(defined as the temperature where the maximum cohesion occurs on the temperature scale) exists with a reasonable correlation is observed (Figure 5). This correlation can be expected because the penetration at $25^{\circ} \mathrm{C}$ can be considered a surrogate for the asphalt binder stiffness. This relationship supports the concept that the maximum cohesion appears to occur at an equal-binder stiffness value as it typically occurs in other ultimate property tests.

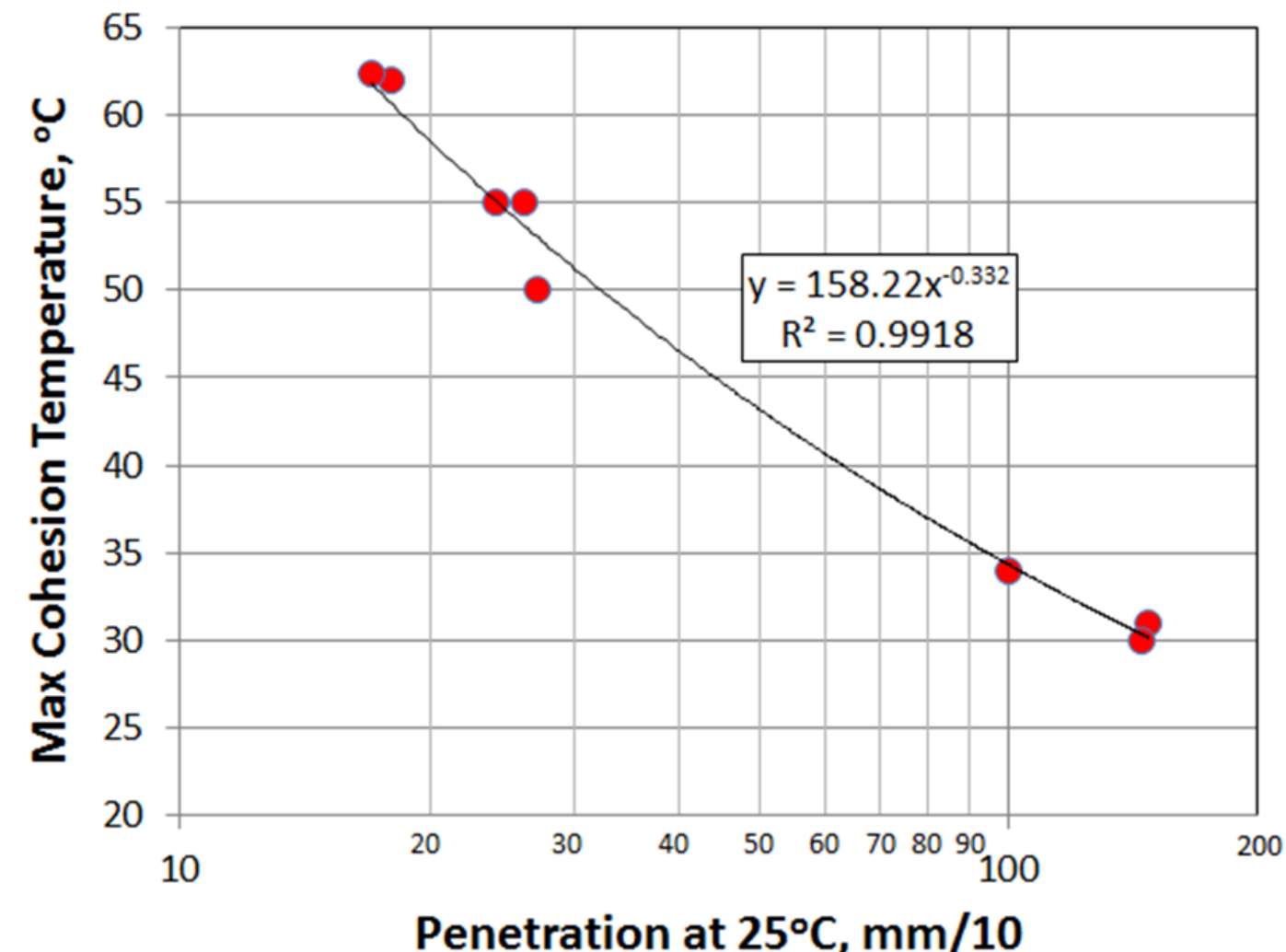

Figure 5. Relationship observed between Penetration and Maximum Cohesion Temperature

Earlier, Rowe and Sharrock (2004) presented the concept that the difference in the energy peak obtained from direct tension testing, where the area under the stress strain curve was available for multiple temperatures, can be compared to the Vialit test results. Both tests have a clear brittle to ductile testing range and both tests have a clear peak in the plot of results obtained when expressed as energy of cohesion. The difference in the peak locations in the two types of tests can be related to loading time as indicated in Figure 6 whereas the width of the peak in the temperature scale representation is related to the rate of loading differences in the two tests. These aspects are discussed further in the following sections. 


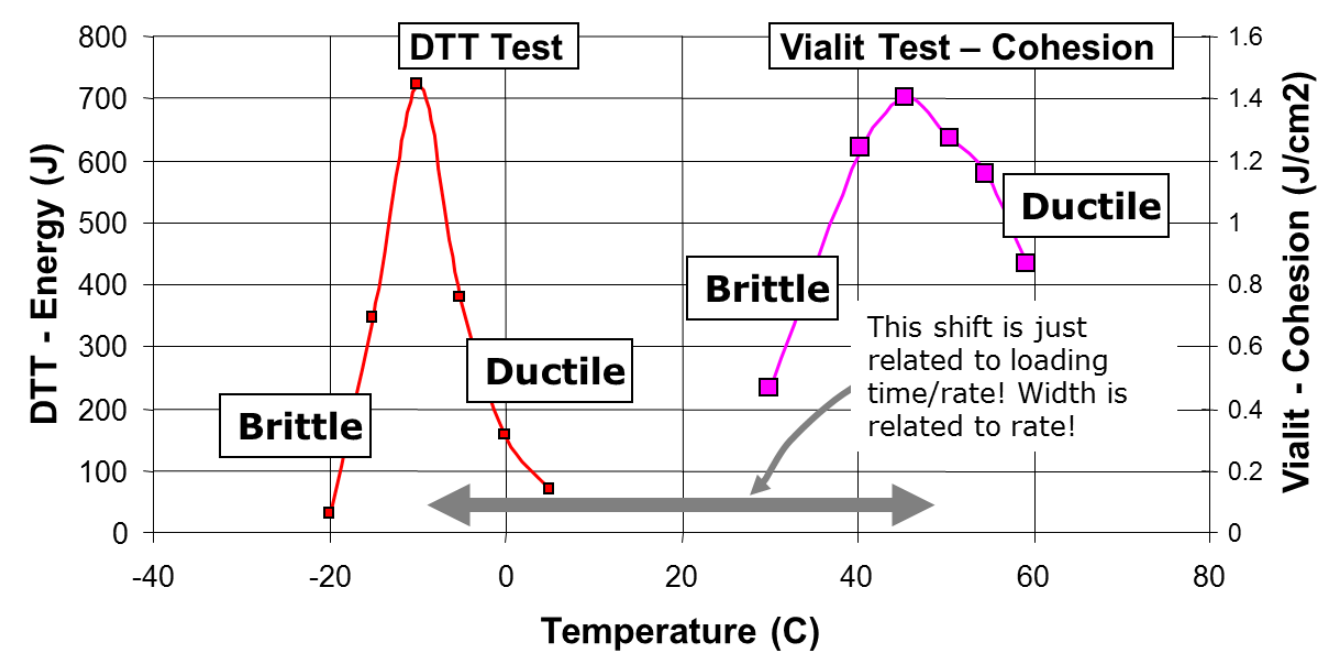

Figure 6. Comparison of Energy dissipated in a DTT fracture test versus cohesion in a Vialit Cohesion Pendulum test

\section{Experimental}

To assess the equivalent loading rate that would correspond to an assumed peak of $15 \mathrm{MPa}$, a series of tests have been conducted. These include BBR and DSR testing of asphalt binder samples to determine the master curve properties. From the master curve data, the binder stiffness of $15 \mathrm{MPa}$ can be determined over a large rate of loadings and frequencies using interpolation techniques. The initial analysis has been conducted with a PG 76-22 binder and further work is being conducted with four SHRP binders being evaluated.

As part of the selection of a temperature window over which to consider a brittle ductile transition, the $\mathrm{G}^{*}=15 \mathrm{MPa}$ criteria has been adopted as an approximate location for the peak in the energy plots. It was also considered that, when the $S(t)$ reaches $300 \mathrm{MPa}$, as defined by the SHRP low temperature parameter, the material should be behaving in a brittle manner. These assumptions provide two stiffness values which can be used to consider a brittle to peak toughness transition range. The next step of the analysis conducted was to determine a suitable value of $G^{*}$ that corresponds to $S(t)=300 \mathrm{MPa}$ so that the full analysis in the frequency domain could be conducted. For this assessment, the data from 6-SHRP core asphalt binders (AAD, AAF, AAG, AAK \& AAM), all after pressure aging conditioning and testing in the BBR at multiple temperatures, were analysed. In the analysis of the SHRP asphalt binders, the values of stiffness from the BBR test have been converted to $G^{*}$ values using the Hopkins and Hamming transformation from $S(t)$ to $E(t)$ and then by completing the transformation by fitting a relaxation spectrum to the data and performing an inter-conversion. This analysis was performed using commercial software which conducts the transformations in a seamless and automatic manner. This approach avoids errors introduced by the simply applied approximation where $\mathrm{G}^{*}$ is taken a $\mathrm{E}(\mathrm{t}) / 3$. The relationships produced for the $\mathrm{G}^{*}$ and phase angle conversions are illustrated in Figure 7. A very good fit is obtained for the interconversion between $\mathrm{G}^{*}$ and $\mathrm{S}(\mathrm{t})$ and, from this analysis, it can be assumed that, when $\mathrm{S}(\mathrm{t})$ equals $300 \mathrm{MPa}$, the corresponding $\mathrm{G}^{*}$ would be $111 \mathrm{MPa}$. 
The data obtained from the Vialit testing with the NuStar PG76-22 using this initial work are shown in Figure 8 with the temperature corresponding to the peak in the cohesion curve being $53.1^{\circ} \mathrm{C}$. NuStar supplies asphalt binder in the USA and typically the grade PG76-22 will be a polymer-modified grade.

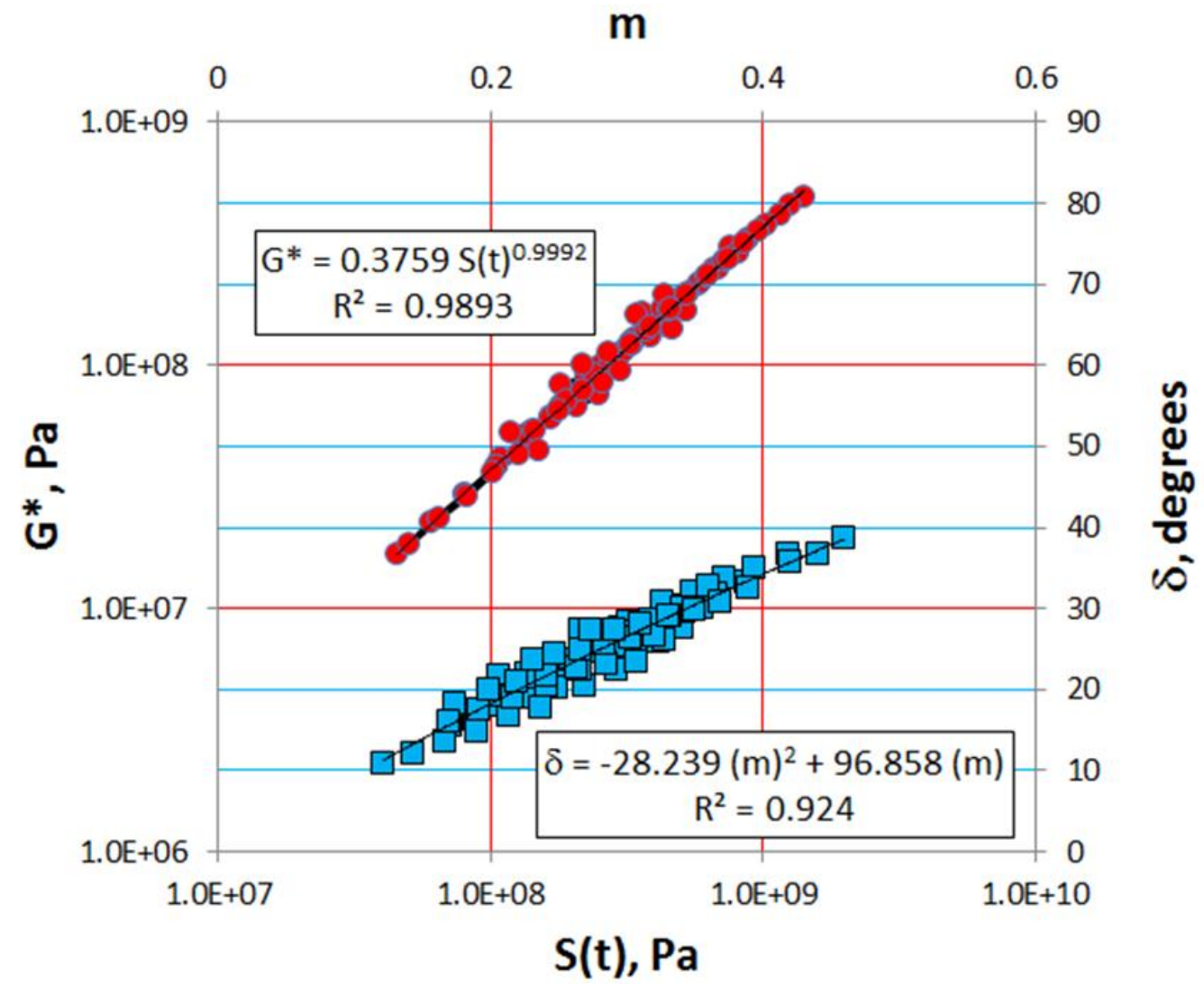

Figure 7. Interconversions of $S(t)$ and $m$-value to $G^{*}$ and phase angle ( $\delta$ ) for SHRP asphalt binders AAD, AAF, AAG, AAK and AAM (all in PAV condition)

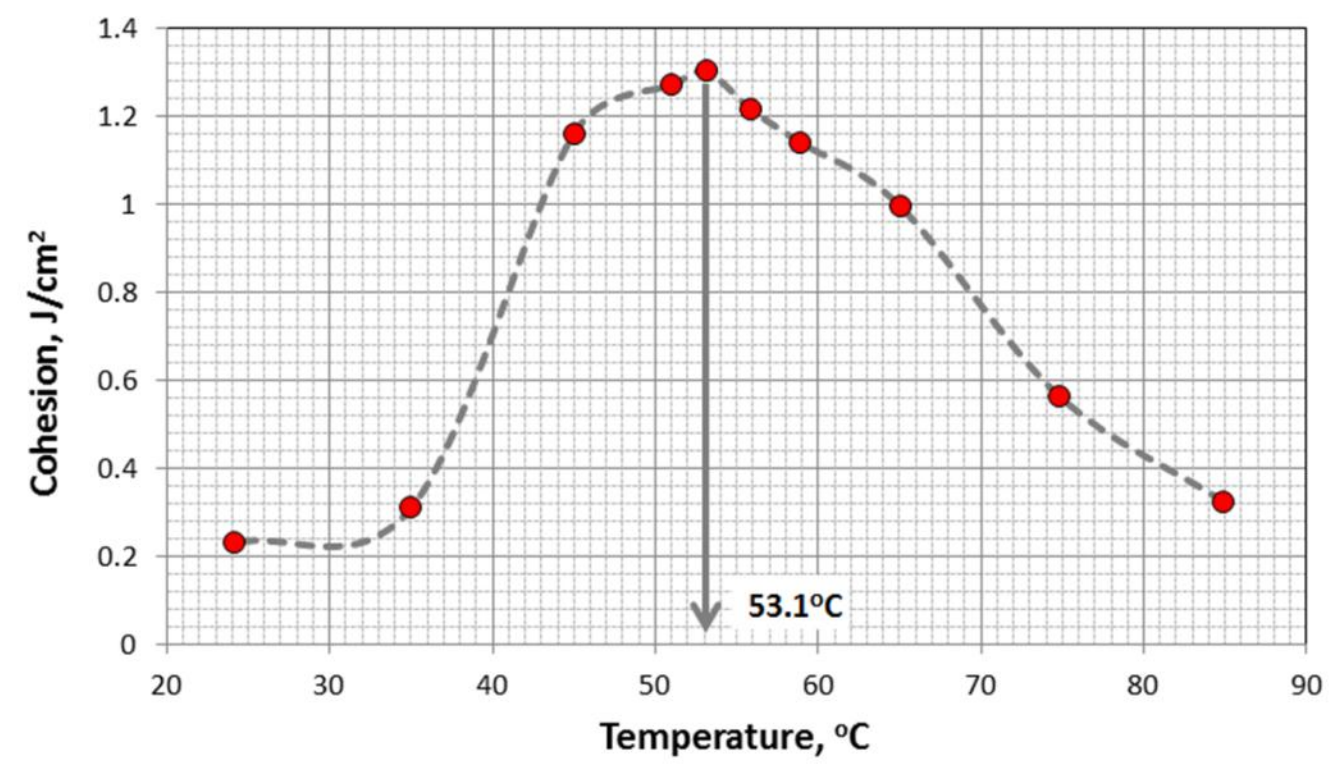

Figure 8. Cohesion versus temperature for a NuStar PG76-22 binder 
Using the principles of time-temperature superposition, a master curve was developed for this binder as shown in Figure 9. The data were collected using both a BBR and a DSR over the temperature range 70 to $-28^{\circ} \mathrm{C}$. The $\mathrm{BBR}$ data were converted to dynamic data using the RHEA ${ }^{\mathrm{TM}}$ software. In developing this curve, the shifting method used was that developed by Gordon and Shaw (1994) and the shift factors were fitted to a Kaelble modified Williams-Landel-Ferry (WLF) equation as described by Rowe and Sharrock (2011) with parameters C1, C2 and Td of 27.18, 108.76 and -28 respectively. A discrete spectra was then fitted to the master curve (Baumgaertel and Winter, 1989) and interpolations were performed using this spectra information enabling isochrones of stiffness to be plotted for a wide range of frequencies. The relaxation strengths, $\left(\mathrm{g}_{\mathrm{i}}\right)$ and associated reciprocal of the relaxation times $\left(1 / \lambda_{\mathrm{i}}\right)$ for each of the relaxation components (i) are also plotted in Figure 9 along with dashed lines representing how each component contributes to the overall relaxation estimated complex modulus, $\mathrm{G}^{*}$ (shown as a solid curve passing through the $\mathrm{G}^{*}$ data points) and phase angle, $\delta$ (shown as solid line passing through the phase angle data).

The effect of the polymer can be seen when inspecting the shape of the phase angle versus frequency. The flattening of this curve as the binder stiffness reduces is typical of the polymer network providing structure at lower stiffness values.

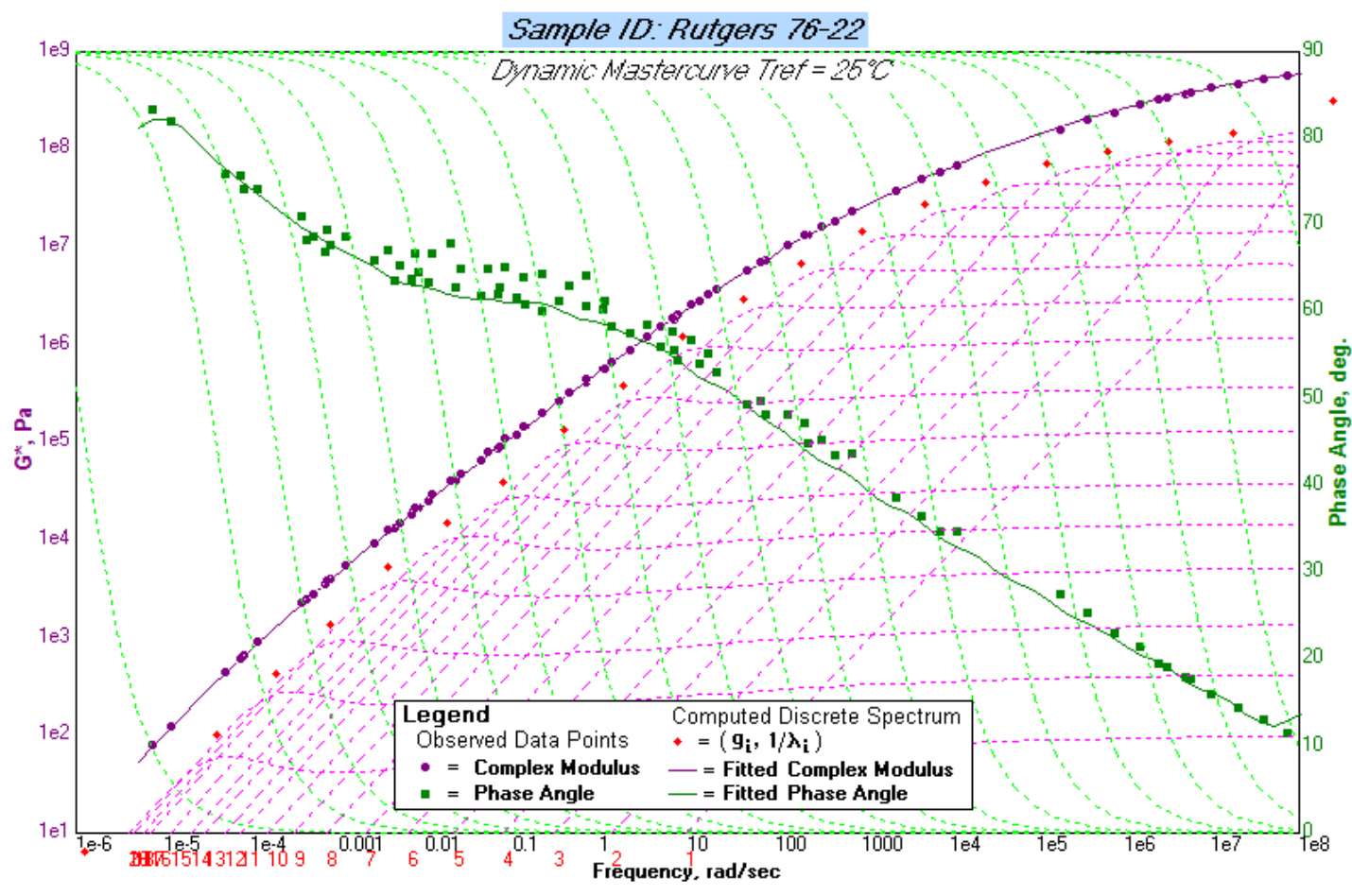

Figure 9. Master curve for PG76-22 binder at a reference temperature of $250 \mathrm{C}$

The loading frequency that corresponds to a stiffness $\mathrm{G}^{*}$ of $15 \mathrm{MPa}$ can be determined and this was computed to be 133,000 radians per second. The exact interpolation was aided by the use of the RHEA ${ }^{\mathrm{TM}}$ software and the interpolation facilities provided therein using the discrete spectra analysis of the data. For the SHRP core asphalt binder AAD, a similar analysis was conducted and the equivalent loading rate was computed as 126,259 radians per second, which is similar to the number produced for 
the modified grade. While a couple of preliminary data sets show that the frequency conversion in this test is greater than $100,000 \mathrm{rads} / \mathrm{s}$, the variability in the number is currently unknown because only a limited number of results are currently available. A few degrees Celsius difference in the peak determination will affect the frequency considerably and, while the two numbers appear very close, it would be expected that the range of frequency conversions to be obtained at the end of this test programme may span a decade. Some preliminary results with other binders support this view. The variability will be more fully understood when the entire test programme has been completed but it is anticipated that the variability will be best considered on a logarithmic scale, as for many parameters associated with rheological and fracture analysis.

The speed of the Vialit pendulum is approximately $4.4 \mathrm{~m} / \mathrm{s}$ as it strikes the asphalt binder specimen, which seems quite slow compared to the rates of loading discussed above. At the point of impact, a load is ramped rapidly within the specimen as its velocity rapidly changes from zero to that of the pendulum. The use of impact loads, such as experienced in this test, results in very fast loading rates and the rate of loading that is experienced in the specimen is far from what could be deduced from the speed of the pendulum.

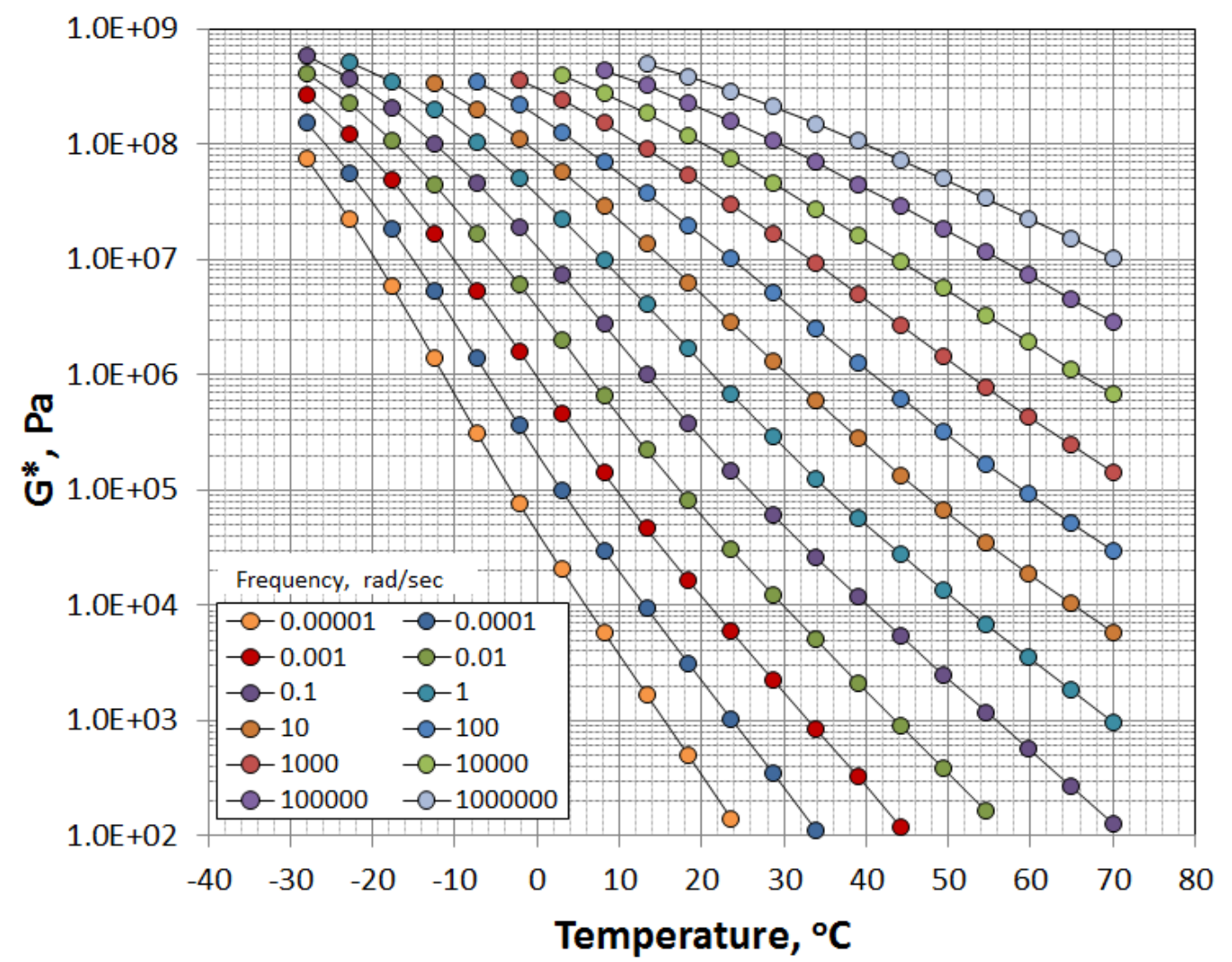

Figure 10. Isochrones of $G^{*}$ produced using the relaxation spectra obtained for the PG76-22 binder

Figure 6 shows a typical DTT versus Vialit test result plotted versus temperature. From this plot, it can be observed that the range from brittle to ductile transition in the DTT test appears smaller than that which is obtained in the Vialit test. In Figure 11, a DTT data set is plotted in which an addition has been made of the temperature at 
which the binder reached a stiffness of $300 \mathrm{MPa}$ in the BBR at a time of loading of 60 $\mathrm{s}$ (indicated by the $\mathrm{T}_{\text {crit }}$ arrow). The stress, strain and energy obtained are shown. At the higher temperatures, the DTT reaches a limiting strain (around 30\%) because of a constraint of the test apparatus and, consequently, the values above $-5^{\circ} \mathrm{C}$ are most likely reach a limiting conditioning for the test equipment. The width of the area with higher energy dissipation (higher toughness) is considered describable for fracture properties. The peak in a DTT test typically occurs at a temperature which is typically about $12^{\circ}$ higher than the critical cracking temperature, as shown in Figure 11. One of the key aspects when comparing tests is to have a proper consideration of the relative loading times at the failure event in order to ensure that time and temperature of loading are both adequately accounted for. In the DTT test, a constant deformation rate of $1 \mathrm{~mm} / \mathrm{min}$ is used with a effective specimen gauge length of $33 \mathrm{~mm}$ enabling the computation of strain as a function of time. For a range of materials, the loading time was computed at the failure condition and using data from BBR tests in order to determine the relaxation modulus, $\mathrm{E}(\mathrm{t})$, that would correspond to this condition. The data and relationship produced are given in Figure 12. For a stiffness that would correspond to $300 \mathrm{MPa}$, a loading time can be deduced to be approximately $43 \mathrm{~s}$ from the DTT test using the relationship obtained in this figure which would approximate to a frequency of $0.023 \mathrm{rads} / \mathrm{s}$ (assuming that $\omega=1 / \mathrm{t}$ ). At this loading time, $\mathrm{G}^{*}$ is assumed to approximate to $111 \mathrm{MPa}$, as discussed earlier in this paper.

A second isochronal plot has then been generated which considers just these two loading times, $0.023 \mathrm{rads} / \mathrm{s}$ and 130,000 rads/s, corresponding to the approximate DTT loading time and the Vialit loading time, see Figure 13. Also shown on this plot is the two critical conditions discussed earlier. These are the value of $\mathrm{G}^{*}$ corresponding to a brittle condition, taken as $111 \mathrm{MPa}$, and the value of $\mathrm{G}^{*}$ corresponding to a peak toughness, as observed in earlier DTT tests and suggested by the work of Heukelom of $15 \mathrm{MPa}$ and consistent with the data plotted in Figure 2. These values would provide an indication of the width of an "energy" plot for the two loading conditions towards the brittle side of the transition. The values deduced are shown as $11.5^{\circ} \mathrm{C}$ and $23.5^{\circ} \mathrm{C}$, respectively. These values seem reasonable when inspecting Figure 6, Figure 8 and Figure 11. The difference in shape of curve and the fact that the DTT curve covers a narrower temperature range from the Vialit test is entirely consistent with the rheology and the principles of time temperature superposition when inspecting the slopes of the curves developed in Figure 13.

The performance of different binder systems in this test is very large as indicated in Figure 14. For the conventional grades, the maximum cohesion is considerably reduced and the width parameter at a given value of cohesion (typically $5 \mathrm{~kJ} / \mathrm{m}^{2}$ ) is also lower. 


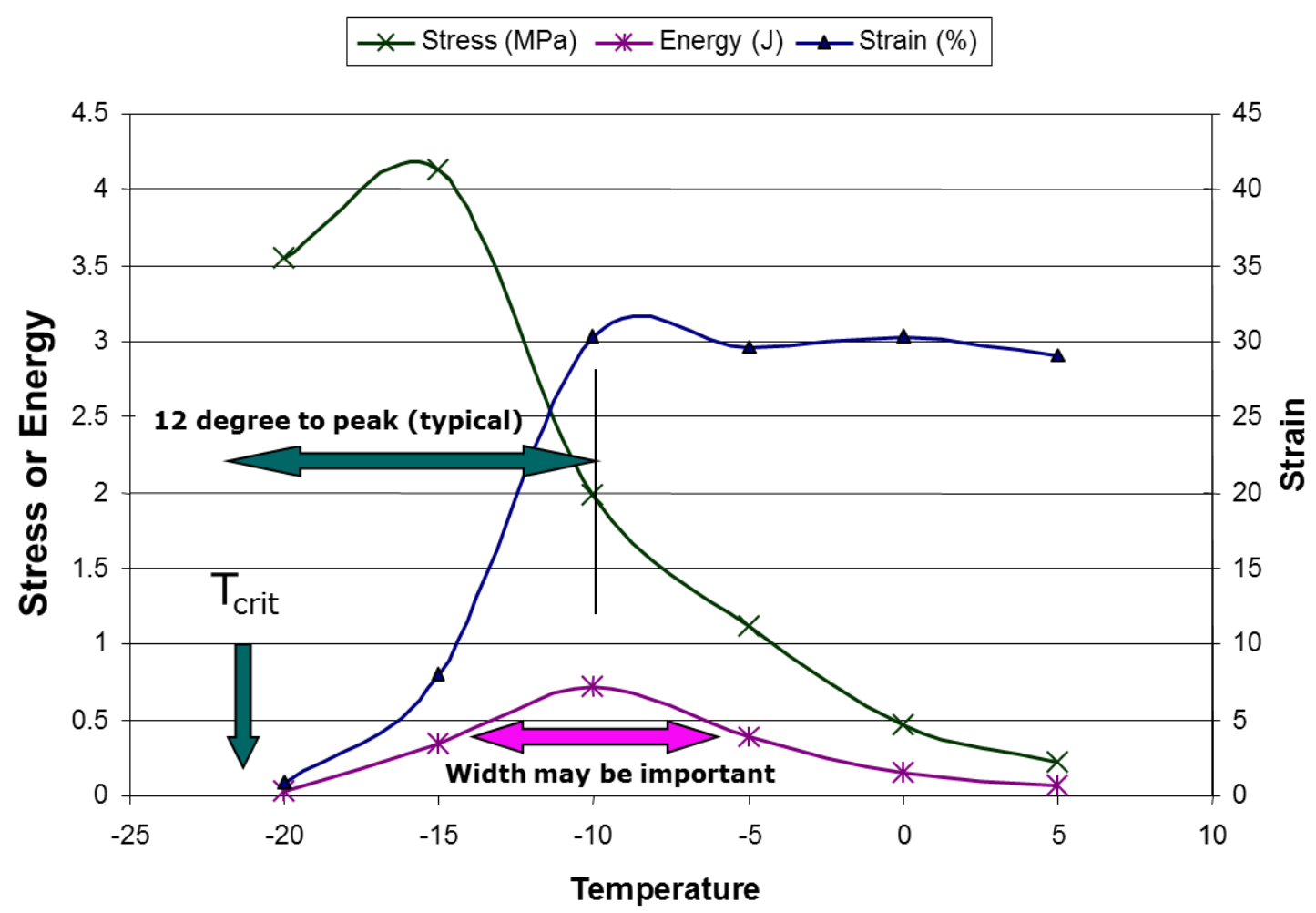

Figure 11. DTT data represented as stress, strain and energy at a break condition (Rowe and Sharrock, 2004)

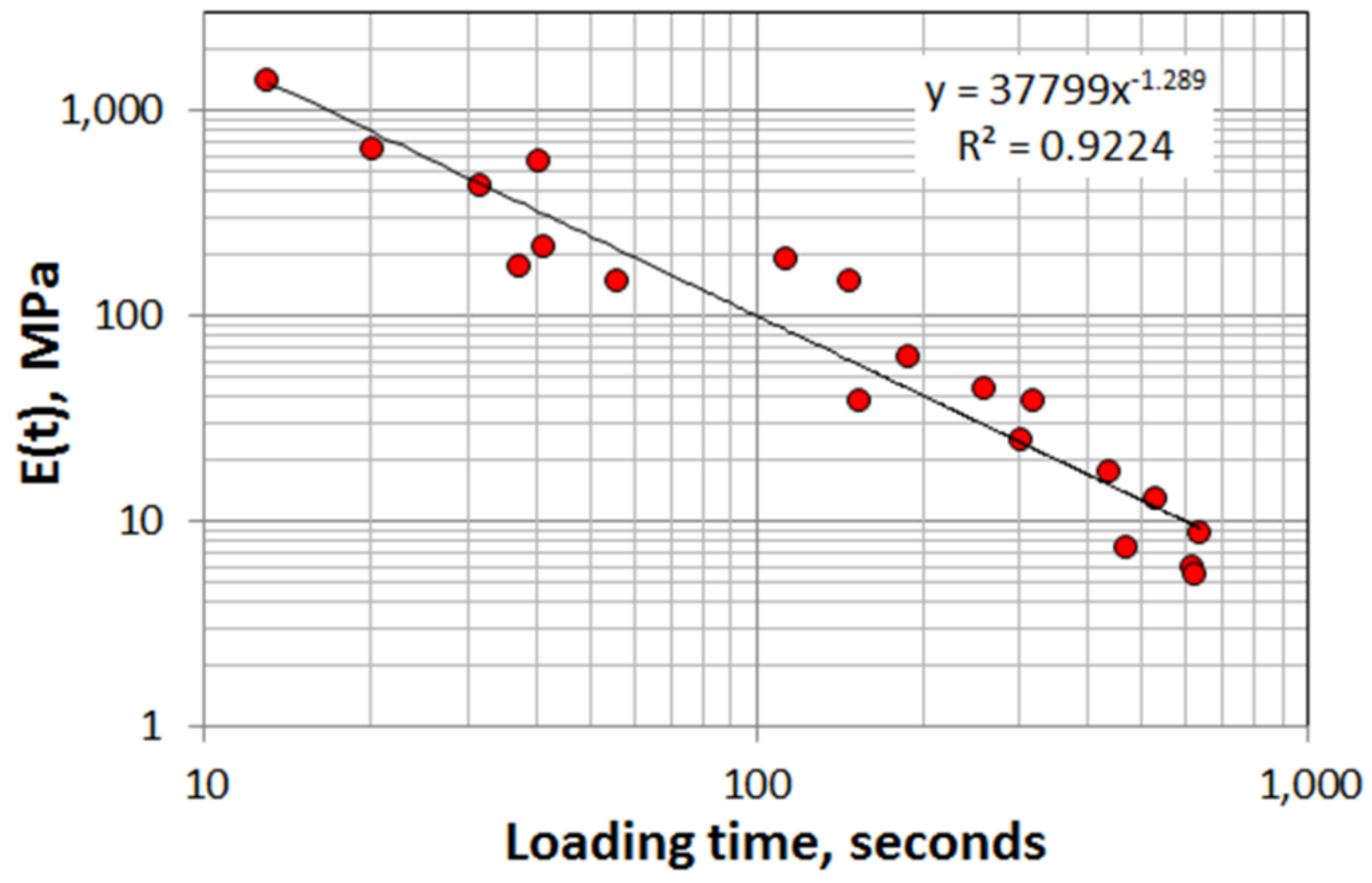

Figure 12. E(t) versus loading time at failure for various DTT tests (after Rayner and Rowe, 2004) 


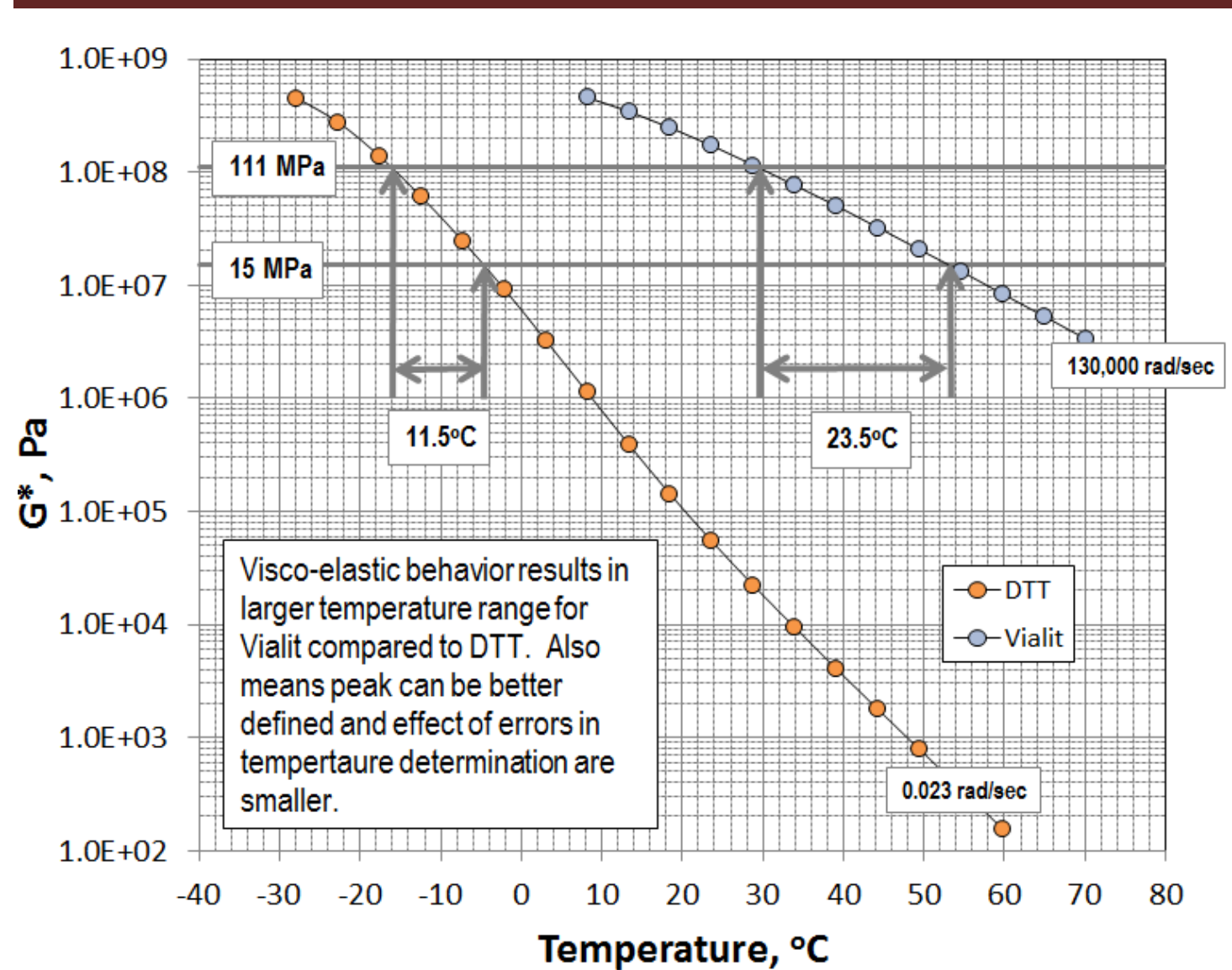

Figure 13. Computation of isochrones corresponding to loading times deduced for the DTT test and the Vialit tests

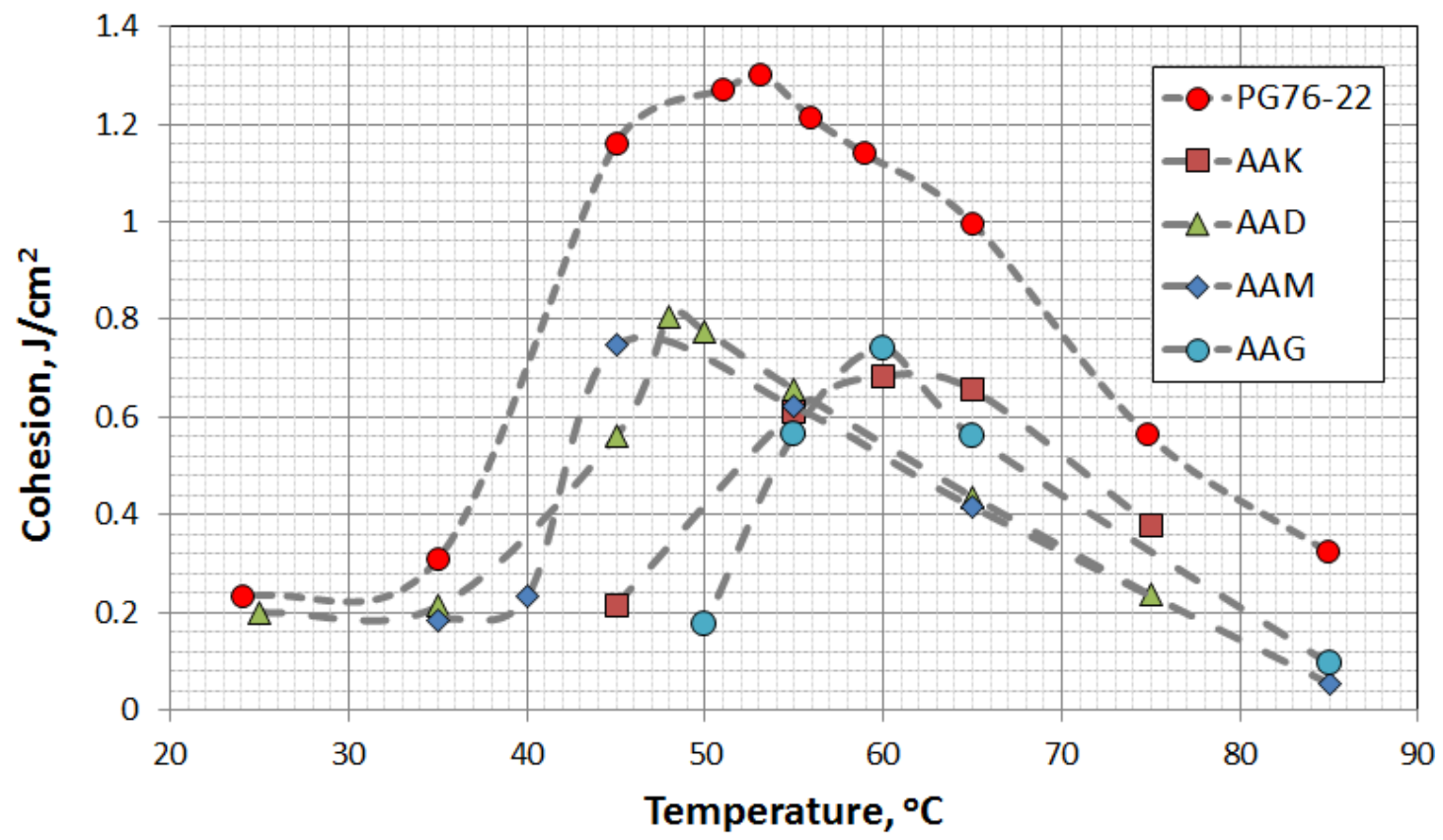

Figure 14. Comparison of a modified PG76-22 versus four SHRP PAV-aged asphalt binders in the Vialit Pendulum test 


\section{Discussion}

It has been demonstrated that the rate of loading in two very different tests, Vialit pendulum and DTT, can be used to explain the differences observed in the brittle to ductile transition area on the temperature scale. The transition zone is bigger in the Vialit test because of a faster rate of loading. The understanding of the effects of rheology via time-temperature superposition enables a better understanding of the material properties and helps to distinguish test artefacts versus true material performance. In direct tension tests, it is well known that the use of polymermodified binder will increase the stress, strain and energy at which failure occurs. This increase was one of the reasons for the development of the critical cracking temperature procedure implemented in AASHTO and ASTM specifications that captured the increased strength properties of polymer-modified binders (Bouldin et al., 2000). However, the same brittle to ductile transition that can be captured in a DTT test at low temperatures can be related to a brittle to ductile transition in a Vialit test at a significantly higher temperature. This translation occurs because, in the temperature range of interest covered by these two tests, no first order transitions in the materials properties are occurring. The DTT test is conducted above the glass transition temperature in nearly all cases and the Vialit test is conducted below temperatures associated with polymer melting points. Thus, in the range of temperatures covered by these tests, the material is generally behaving as a thermorheologically simple material in which the principles of time-temperature supposition are valid. That said, in a few circumstances, the presence of wax and/or wax like modifiers may marginally impact this assumption in certain asphalt binders.

In recent years, many tests have been developed to characterize ultimate properties. These have included tests to capture the performance of bond between layers, cracking of binders, durability of reclaimed asphalt binders and other properties. Often, the test methods have been developed at a single temperature and measure a property such as tensile strength or bond strength. For example, a well-known test in Europe is the Leutner shear test for assessment of bond between two layers. The loading rate in this test is a constant rate of deformation of $50 \mathrm{~mm} / \mathrm{min}$ and the test is conducted at a standard temperature of $20^{\circ} \mathrm{C}$. In the USA, similar versions of this test have been implemented in specifications using a test temperature of $25^{\circ} \mathrm{C}$. The use of a single loading rate and single temperature enables one point to be captured on a curve of an ultimate property (be in stress, strain or energy) versus temperature or a reduced property such as binder stiffness. The "cohesion" of a material is important for bond because a "cohesive" bond is required between two asphalt mixture layers. Consequently, a test at a single condition does not fully define material performance but rather only gives a single point on a curve. The use of strength alone can also be deceiving because high strengths are often obtained close to a brittle condition. For a material to perform well, performance is required over a range of temperatures associated with a particular climatic zone and loading times associated with the applied loading/traffic.

In the Vialit test, the performance range is often captured as indicated in Figure 3. Typically, this range is captured at $5 \mathrm{~kJ} / \mathrm{m}^{2}$ (British Board of Agrément, 2010). This range in performance for non-modified binders is related to the shape of the master curve, as expressed by the R-value in the generalized form of the CAM model (Rowe and Sharrock, 2011) which is also a descriptive parameter for describing the 
relaxation spectra or relaxation properties of the asphalt binder. Data for the four SHRP asphalt binders evaluated are shown in Figure 15. The high degree of correlation obtained is strongly influenced by the considerably different rheology obtained with the AAG binder (see Figure 16) which has a very low asphaltene content compared to the other binders. The importance of a critical temperature range being related to the overall shape of the master curve is entirely consistent with expectations. The temperature range for the modified binder was $39^{\circ} \mathrm{C}$. Clearly, with this type of modification the range is impacted by both the base binder and the modifier.

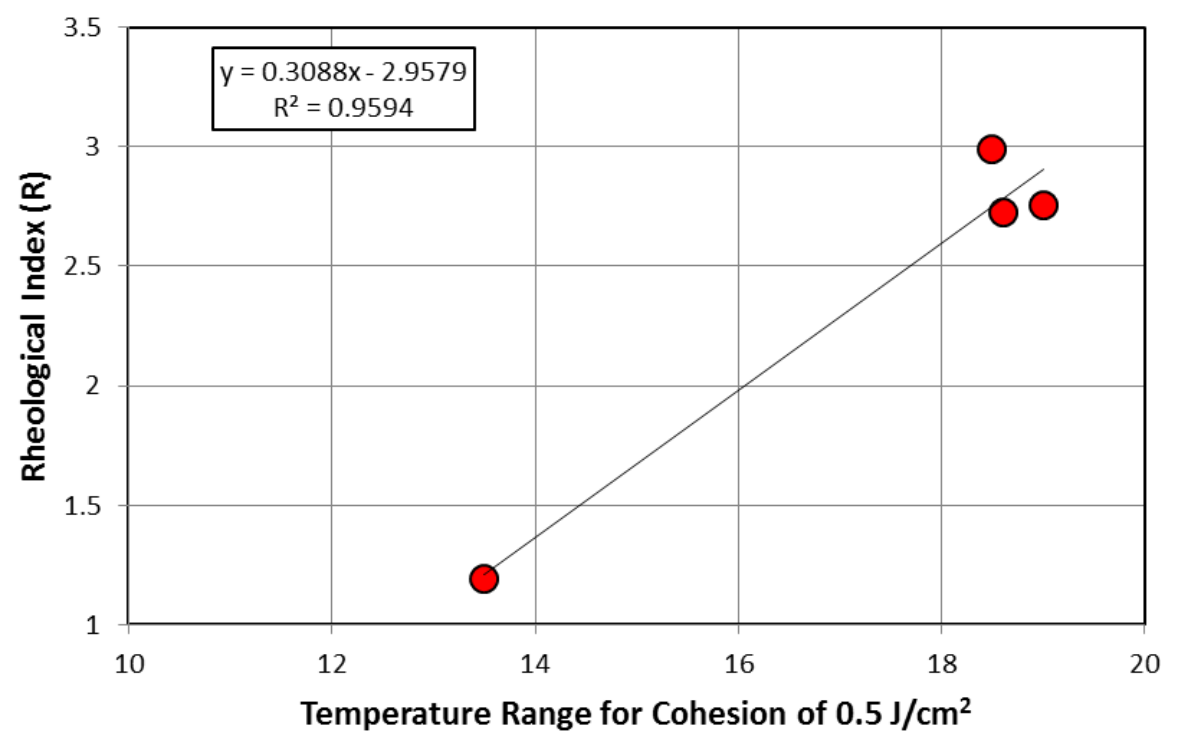

Figure 15. Temperature range for Cohesion of $0.5 \mathrm{~J} / \mathrm{cm} 2$ versus $R$-value for four SHRP core asphalt binders

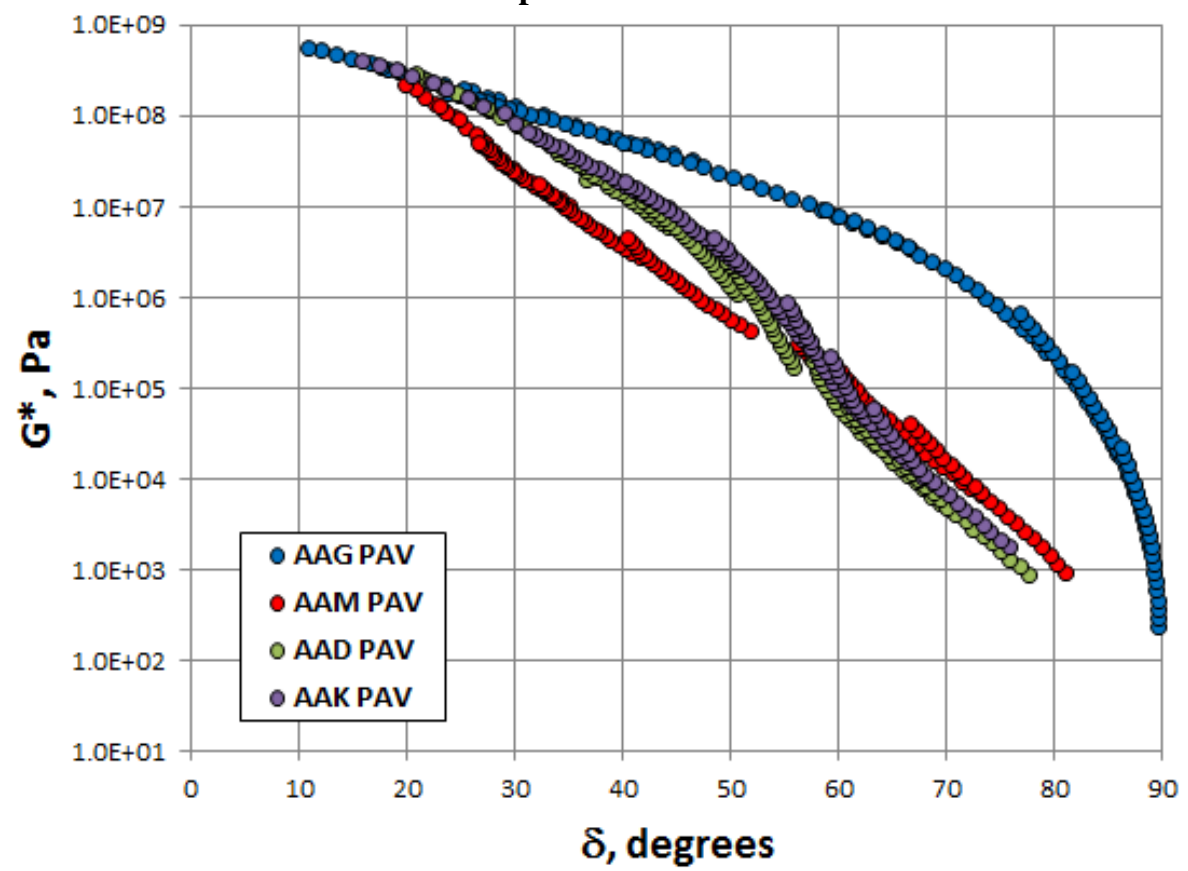

Figure 16. Rheology of SHRP core asphalt binders in PAV aged condition shown in Black space plot 
Thus, based upon the rheological observations, the range in performance in the ultimate property tests appear to be related to the overall rheology of the unmodified binder. As modifiers are introduced, the range in performance is then extended. The critical temperature at which performance is achieved appears to be related to the hardness or stiffness of the binder. This performance temperature can be influenced by the degree of processing for a binder. For example, if a source with a given Rvalue exists, the PG grade (in USA specifications) or Penetration (in European specifications) will control temperature at which performance is achieved. Furthermore, if stiffness of the binder is estimated from the penetration from the relationship developed by Rowe and Baumgardner (2011), the data previously presented in Figure 5 can be combined with the more recent data developed for the SHRP core asphalt binders and the PG76-22 as illustrated in Figure 17. Thus, it would appear that the position of the peak in cohesion can be related to the binder stiffness characteristics. In addition, the interrelationships with rheology and chemistry of a particular source also exist; for example, the estimation of R-value as a function of chemical fractions has been well established (Christensen and Anderson, 1992; Baumgardner, 2013; Scarsella and Mastrofini, 1999). Consequently, in the development of formulations and binder grades, a strong dependency upon source properties and performance can be deduced for compliance with ultimate properties as well as binder grades such as those specified the AASHTO and CEN specifications.

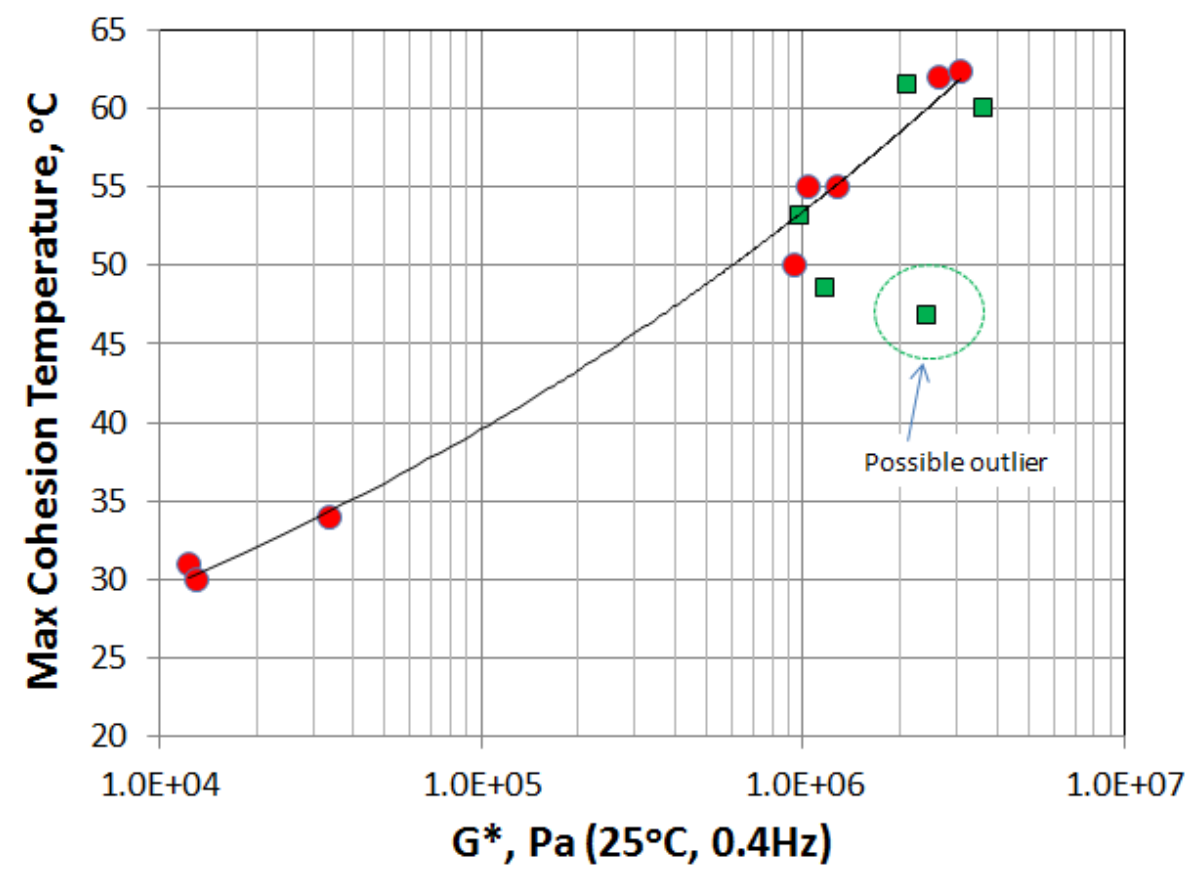

Figure 17: Stiffness versus peak cohesion temperature

\section{Conclusions}

The Vialit pendulum testing, as standardized in CEN standards, provides another method of characterizing a brittle to ductile transition that occurs in asphalt binders. The properties are defined at a very high rate of loading and the work has been conducted to deduce the loading rates that apply in this test. In European standards, the magnitude of the peak that occurs (peak cohesion) and the breadth of the curve are 
considered important properties. The position on the temperature scale of the peak cohesion is also recorded and reported.

In this work, some information related to a conceptual framework for analysis of ultimate property tests is presented. The key findings to date are as follows:

- Preliminary data suggest that the equivalent loading rate using dynamic oscillatory measurements is around 120,000 to 130,000 rads/s.

- The temperature range, which covers the brittle to ductile transition, must be considered as a function of loading rate. At faster rates, a larger temperature ranges results.

- The test discriminates between modified and conventional asphalt binders as demonstrated by the comparison between SHRP core asphalt binders and a modified PG76-22.

- Preliminary evaluation of data demonstrate a relationship between the rheological index (R-value) and the cohesion range in the Vialit test.

The work demonstrates the importance of rheology in understanding fracture and cohesion in a simple test such as the Vialit pendulum test. The rheological considerations can be applied to the understanding of results from other tests. To fully capture a materials performance window, it is very important to conduct tests at more than one temperature because single point tests can be misleading when a bell shape curve exists for cohesion energy and fracture properties. Only full consideration of the time-temperature aspects can fully describe a materials ultimate property characterization. The preferred method to consider performance of a material is to plot the data obtained as a function of binder stiffness, capturing the time and temperature effects in this parameter when possible.

Additional work is currently being performed with this test method and binders used for this study. It is hoped that, within the next year, considerably more data will be available including for a series of binders used in today's market in the USA along with a full analysis of the older SHRP binders that are still available for testing. Some additional DTT testing work is also planned and these results will be reported on in future papers.

\section{Acknowledgments}

The author gratefully acknowledges contributions from the Rutgers Asphalt Materials Laboratory for use of the facilities, the contribution of equipment from Cooper Technologies in the United Kingdom and James Cox and Sons. Furthermore this work would not have been possible without assistance from the Asphalt Institute and Mike Anderson who prepared all the samples for testing and the work of the Binder Expert Task Group for developing a work to address intermediate temperature properties. In addition, the authors would like to acknowledge the assistance of $\mathrm{Mr}$. Martin Heslop for providing some of the ideas with regard to use of this test method in evaluating the performance properties of modified binders. 


\section{References}

Anderson, D.A., Christensen, D.W., Bahia, H.U., Dongre, R., Sharma, M.G., Antle, C.E and Button, J., "Binder Characterization and Evaluation, Volume 3: Physical Characterization", SHRP-A-369, Strategic Highway Research Program, National Research Council, Washington, DC 1994.

Baumgaertel, $\mathrm{M}$ and Winter, H.H., "Determination of discrete relaxation and retardation time spectra from dynamic mechanical data", Rheol Acta 28:511-519, 1989.

Baumgardner, G.L., "Rubber Modified Binders and Mixtures", Presentation at the $56^{\text {th }}$ New Jersey Asphalt Paving Conference, 5-6 March, 2013.

British Board of Agrément, "Colas Modified Bitumen Road Emulsions, Sufix 80S, Prinmuls Lite LMP90X, Premium 80 and Prinmuls MP90X Road Emulsions," HAPAS - Highways Authorities' Product Approval Certificate, Agrément Certificate 10/H162, September 2010.

Bouldin, M.G., Dongré, R.N., Rowe, G.M., Sharrock, M.J. and Anderson, D.A., "Predicting Thermal Cracking of Pavements from Binder Properties - Theoretical Basis and Field Validation", Proceedings, Journal of the Association of Asphalt Paving Technologists, Volume 69, 2000.

Christensen, D. W. and Anderson, D.A., "Chemical-Physical Property Relationships for Asphalt Cements and the Dispersed Polar Fluid Model," Vol. 37, No. 3 \& 4, Division of Fuel Chemistry, American Chemical Society, Preprints of Papers, 204th ACS National Meeting, Washington, D. C., pp. 1279-1291, August 1992

Comité Européen de Normalisation, "Bitumen and bituminous binders - Framework for specifying cationic bituminous emulsions", EN 13808, 2005.

Comité Européen de Normalisation "Bitumen and bituminous binders - Determination of cohesion of bituminous binders with pendulum test", EN 13588, 2008.

Comité Européen de Normalisation, "Bitumen and bituminous binders - Framework for specifying cut-back and fluxed bituminous binders" EN 15322, 2009.

Gordon, G.V. and Shaw, M.T., "Computer Programs for Rheologists", Hanser/Gadner Publ., 1994.

Heukelom, W, "Observations on the Rheology and Fracture of Bitumens and Asphalt Mixes", Proceedings, Association of Asphalt Paving Technologists, Volume 35, 1966, pp. 358-399

Highways Agency, Transport Scotland, The National Assembly for Wales and The Department for Regional Development Northern Ireland "Determination of Cohesion of Bitumen and Bituminous Binders", Manual of Contract Documents for Highway Works, Volume 1, Clause 957 - Specification for Highway Works, 2008. 
Pérez-Jiménez, F., Valdés, G.A., Botella, R., Miró, R. and Martínez, A., “Approach to fatigue performance using Fénix test for asphalt mixtures", Construction and Building Materials, Elsevier, No. 26, 2012, pp. 372-380.

Rayner, C. and Rowe, G.M, "Properties of Mastics Using Different Fillers with Both Unmodified and EVA-Modified Binders", Proceedings, Eurasphalt \& Eurobitume Congress, Vienna, April 2004.

Rowe, G.M. and Sharrock, M.J. "The Direct Tension Test and the Behavior of Asphalt Binders at Low and Intermediate Temperatures", The 4th International symposium on Binder Rheology and Pavement Performance, Scottsdale, Arizona, September 22-23, 2003.

Rowe, G.M. and Sharrock, M.J., "Alternate shift factor relationship for describing the temperature dependency of the visco-elastic behavior of asphalt materials", TRB Annual Meeting, Published in the Journal of the Transportation Research Board, No. 2207, Asphalt Materials and Mixtures, Volume 1, Washington DC, 2011, pp. 125135.

Scarsella, M. and Mastrofini, D., "Petroleum Heavy Ends Stability: Evolution of Residues: Macrostructure by Aging”, Energy \& Fuels 1999, 13, 739-747.

Smith, T.L. "Dependence of the Ultimate Properties of a GR-S Rubber on Strain Rate and Temperature", Journal of Polymer Science, Volume 32, 1958, pp. 99-113.

Surrey County Council, "A Review of Rhinophalt Preservative The preventative maintenance system by ASI Solutions" Surrey County Council Asset Planning Group, September 2011.

Total Bitumen, "Emulsis Footpath ${ }^{\circledR}$ Polymer Modified Footway Surface Dressing Emulsion," Technical Data Sheet, February 2007.

Van der Poel, C.J., "A General System Describing the Visco-Elastic Properties of Bitumens and its relation to routine test data," Journal of Applied Chemistry, Volume 4, 1954, pp. 221-236. 